\title{
Disparities In The Use Of Drugeluting Stents For Diabetic Patients With ST-elevation Acute Myocardial Infarction Assisted In the Public versus Private Network - VICTIM Register
}

\author{
Jussiely Cunha Oliveira, ${ }^{1,2}$ Laís Costa Souza Oliveira, ${ }^{1,3}$ Jeferson Cunha Oliveira, ${ }^{1,3}$ Ikaro Daniel de Carvalho Barreto, ${ }^{4 \bullet}$ \\ Marcos Antonio Almeida-Santos, ${ }^{5 \oplus}$ Ticiane Clair Remacre Munareto Lima, ${ }^{1 \oplus}$ Larissa Andreline Maia Arcelino, ${ }^{1,6}$ \\ Isadora Soares Bispo Santos Silva, ${ }^{7 \odot}$ Antônio Carlos Sobral Sousa, ${ }^{1,7,8,9 \odot}$ José Augusto Soares Barreto-Filho ${ }^{1,7,8,9 \odot}$ \\ Núcleo de Pós-graduação em Ciências da Saúde da Universidade Federal de Sergipe, ${ }^{1}$ Aracaju, SE - Brazil \\ Universidade Tiradentes, ${ }^{2}$ Aracaju, SE - Brazil \\ Hospital Primavera, ${ }^{3}$ Aracaju, SE - Brazil \\ Núcleo de Pós-graduação em biometria e estatística aplicada da Universidade Federal Rural de Pernambuco, ${ }^{4}$ Recife, PE - Brazil \\ Programa de Pós-graduação em Saúde e Ambiente da Universidade Tiradentes, ${ }^{5}$ Aracaju, SE - Brazil \\ Faculdade Estácio de Sá, ${ }^{6}$ Aracaju, SE - Brazil \\ Departamento de Medicina da Universidade Federal de Sergipe, ${ }^{7}$ Aracaju, SE - Brazil \\ Centro de Ensino e Pesquisa da Fundação São Lucas, ${ }^{8}$ Aracaju, SE - Brazil \\ Divisão de Cardiologia do Hospital Universitário da Universidade Federal de Sergipe, ${ }^{9}$ Aracaju, SE - Brazil
}

\begin{abstract}
Background: Primary angioplasty (PA) with placement of either bare metal or drug-eluting stents (DES) represents the main strategy in the treatment of ST-elevation myocardial infarction (STEMI). Diabetic patients, however, represent a special population in STEMI, with high rates of restenosis and unfavorable clinical outcomes, and with the use of DES, level of evidence $A$ and indication class II, being indicated to reduce these damages.
\end{abstract}

Objectives: To evaluate the DES rate of use in patients with STEMI and in the subgroup of diabetics assisted in the public versus private health network in Sergipe.

Methods: This is a population-based, cross-sectional study with a quantitative approach using the data from the VICTIM Register. These were collected in the only four hospitals with capacity to perform PA in Sergipe, from December 2014 to March 2017.

Results: A total of 707 patients diagnosed with STEMI were evaluated, of which 589 were attended at SUS and 118 at the private network. The use of DES in PA was lower in SUS compared to the private network in both the total sample (10.5\% vs $82.4 \%, p<0.001)$ and in subgroup diabetic patients $(8.7 \%$ vs $90.6 \%, p<0.001)$, respectively. In all hypotheses tested, the level of significance was $5 \%(p<0.05)$.

Conclusions: The study reveals a disparity in the use of DES during the performance of PA between the public and private network, both in the total sample and the subgroup for diabetics, with lower rates for SUS users, demonstrating the challenges that need to be overcome in order to achieve quality improvements of the services provided. (Arq Bras Cardiol. 2019; 112(5):564-570)

Keywords: ST Elevation Myocardial Infarction; Drug-Eluting; Diabetes Mellitus; Case-Control Studies; Angioplasty; Hospitals,Private; Hospitals, Public.

\section{Introduction}

The early use of coronary reperfusion therapies is one of the main factors associated with the longer survival of patients with acute ST-segment elevation myocardial infarction (STEMI). In this context, primary angioplasty (PA)

Mailing Address: José Augusto Soares Barreto-Filho •

Av. Gonçalo Prado Rollemberg, 211, sala 202 - Centro de Saúde Prof. José Augusto Barreto. Postal Code 49010-410, São José, Aracaju, SE - Brazil E-mail: jasbf@cardiol.br, joseaugusto.se@gmail.com

Manuscript received March 11, 2018, revised manuscript August 07, 2018, accepted October 02, 2018

DOI: 10.5935/abc.20190054 is the preferred option for this purpose, if started up to 90 minutes after confirmation of the diagnosis of infarction. ${ }^{1,2}$ Coronary stent implantation is considered the device of choice for the completion of angioplasty because its use reduces the rates of acute vessel occlusion, and the need for late surgical revascularization when compared to the procedure performed with balloon alone. ${ }^{3}$

However, diabetic patients diagnosed with STEMI represent a special population because of the greater difficulty of percutaneous treatment. ${ }^{4}$ This group shows high rates of restenosis and is associated with unfavorable clinical outcomes, even with the use of bare metal stents. ${ }^{1,5}$ Thus, the Brazilian Society of Hemodynamics and Interventional Cardiology $(\mathrm{SBHCl})$ recommends the preferential use of the 
drug-eluting stent in diabetics, with evidence level A and indication class II, since these devices release substances that inhibit intimal hyperplasia of the treated vessel, further reducing the chances of restenosis. ${ }^{1,3}$

A major obstacle faced with the use of drug-eluting stents (DES) is the high cost of the device when compared to the bare metal one, in addition to the expenses with prolonged double antiplatelet therapy, which further increases its treatment cost. ${ }^{1,6}$ However, the cost-effectiveness ratio is attractive for the incorporation of this technology when it comes to diabetic patients, since they reflect a lower budget impact by avoiding late complications and the need for future reinterventions. Thus, this device was released for use in the Brazilian Unified Health System (SUS) for the patients above mentioned in 2014, according to ordinance no. 29 of the Ministry of Health. ${ }^{7}$

Therefore, this study aims to evaluate the rate of DES in patients with STEMI, and in the subgroup of diabetic patients assisted in the public versus private healthcare network in Sergipe.

\section{Methods}

The present analysis used data from the VICTIM Register (Vla Crucis for the Treatment of Myocardial Infarction), a study that aims to analyze and compare the access of STEMI patients to hospitals with capacity to perform angioplasty in the public and private networks of the state of Sergipe.

This is a cross-sectional study, with a quantitative approach, developed from December 2014 to March 2017. Data collection was performed in the only four hospitals in the state of Sergipe with capacity to perform AP, all located in the capital city Aracaju. Among these, only one offers service through SUS, and does not have "open door" care, which requires that the patient be referenced from another health institution to be admitted to that hospital. The other three hospitals offer private service, either through health plans or private payment.

To collect data, a study-specific tool, CRF (Case Report Form), was used; data includes information on socio-demographic conditions, onset of symptoms and clinical presentation, hospitalization data, angiographic procedure, patients' progression during hospitalization and up to 30 days after AMI. To be filled, the interview with the patient (or with the relative, when the patient had no clinical conditions) was used as source, besides the analysis of the medical record.

Patients older than 18 years, with a history consistent with AMI, electrocardiographic confirmation of the STEMI according to the defining criteria of the $\mathrm{V}$ Guideline of the Brazilian Society of Cardiology on the treatment of STEMI, ${ }^{1}$ and who signed the Free Informed Consent Term (FIC) were included. Those unable to sign had their participation authorized by a person responsible for them; the illiterate patients gave permission by fingerprint.

The following patients were excluded: those who died before the interview; who did not characterize the Via Crucis, that is, those who were hospitalized for other causes when they had STEMI; those who refused to participate in the survey; those whose acute STEMI event was characterized as reinfarction (occurring within 28 days of the incident infarction); those who had a change of diagnosis - that is, they entered the tertiary hospitals with an initial diagnosis of STEM, but after having undergone exams, another finding was observed; and those attended through a health plan in a philanthropic hospital.

This research was submitted to the Research Ethics Committee of Universidade Federal de Sergipe (UFS) and approved with CAAE no. 23392313.4.0000.5546.

\section{Statistical analysis}

All STEMI patients, representing all the cases treated in the State, were included in the sample, since all the centers with a hemodynamic service were included in the study. To evaluate the association for categorical variables presented in absolute numbers and percentage, Pearson chi-square test was used. Continuous variables were presented by mean and standard deviation and the unpaired Student t-test was used to evaluate the means differences, and its adherence to the normal distribution was tested using Kolmogorov-Smirnov test $(p>0.05)$. In all hypotheses tested, the level of significance was $5 \%(p<0.05)$. The SPSS for Windows Version 17 software was used for statistical analysis.

\section{Results}

\section{Sociodemographic profile}

A total of 707 patients were analyzed, of which $83 \%$ were attended by the public service and $17 \%$ by the private network. In both services, most patients were male $(67.1 \%$ vs $71.2 \%, p=0.382$ ), with a mean age of $61.2 \pm 12.2$ years vs. $62.3 \pm 12.2$ years $(p=0.332)$, respectively. Ethnicity was a variable collected based on the self-declaration of the patients involved. In this context, a statistically significant difference was observed when the two services are compared, with $68.7 \%$ of the SUS patients declaring being non-whites, while $60 \%$ of the patients in the private network declared themselves to be white $(p<0.01)$ (Table 1$)$.

Other expressive data regarding the differences between the patients attended by SUS and the private network are related to social class and educational level. Regarding social class, it can be observed that in the public service $61.2 \%$ of the patients had family income consistent with class $\mathrm{E}$ (gross family income of up to two minimum wages), while in the private network $33 \%$ of the patients were class $\mathrm{C}$ (gross family income from 4 to 10 minimum wages) $(p<0.001)$. Regarding the level of education, $57 \%$ of public service patients studied until elementary school, while $30.5 \%$ of the patients attended by the private network studied until higher education level $(p<0.001)$. It is worth mentioning that about $27 \%$ of the public service patients never studied (Table 1).

\section{Cardiovascular risk factors}

The cardiovascular risk evaluated for patients from SUS and from the private network admitted to the study were: systemic arterial hypertension, diabetes mellitus, dyslipidemia and smoking. In both services, hypertension was shown to be the most prevalent factor $(39.2 \%$ vs $71.2 \%, p=0.033)$, followed by dyslipidemia (33.6\% vs 55.9\%, $p<0.001)$. Diabetes mellitus 
Table 1 - Sociodemographic profile of STEMI patients attended at Sergipe State Hospitals with capacity to perform primary angioplasty (SUS x Private care)

\begin{tabular}{|c|c|c|c|}
\hline Demography & SUS ( $n=589$ ) & Private network $(n=118)$ & $p$ value \\
\hline Age, years (mean $\pm S D$ ) & $61.2 \pm 12.2$ & $62.3 \pm 12.2$ & 0.332 \\
\hline \multicolumn{4}{|l|}{ Gender, $\mathrm{n}(\%)$} \\
\hline Male & $395(67.1)$ & $84(71.2)$ & \multirow[t]{2}{*}{0.382} \\
\hline Female & $194(32.9)$ & $34(28.8)$ & \\
\hline \multicolumn{4}{|l|}{ Ethnicity, n (\%) } \\
\hline White & $179(31.3)$ & $69(60.0)$ & \multirow[t]{2}{*}{$<0.001$} \\
\hline Non-white & $393(68.7)$ & $46(40.0)$ & \\
\hline \multicolumn{4}{|l|}{ Social class, $n(\%)$} \\
\hline$A^{*}$ & $2(0.4)$ & $11(9.8)$ & \multirow[t]{5}{*}{$<0.001$} \\
\hline $\mathrm{B} \dagger$ & $8(1.5)$ & $30(26.8)$ & \\
\hline$C \ddagger$ & $39(7.1)$ & $37(33.0)$ & \\
\hline$D \S$ & $163(29.8)$ & $24(21.4)$ & \\
\hline$E / /$ & $334(61.2)$ & $10(9.0)$ & \\
\hline \multicolumn{4}{|l|}{ Level of Education } \\
\hline Never studied & $161(27.3)$ & $6(5.1)$ & \multirow[t]{5}{*}{$<0.001$} \\
\hline Elementary School & $335(57.0)$ & $29(24.5)$ & \\
\hline High School & $78(13.2)$ & $31(26.3)$ & \\
\hline Higher Education & $12(2.0)$ & $36(30.5)$ & \\
\hline Postgraduate studies & $3(0.5)$ & $16(13.6)$ & \\
\hline \multicolumn{4}{|l|}{ Marital status, $\mathrm{n}(\%)$} \\
\hline Single & $91(15.5)$ & $4(3.4)$ & \multirow[t]{5}{*}{$<0.001$} \\
\hline Married & $298(50.6)$ & $84(71.2)$ & \\
\hline Lives with a partner & $92(15.6)$ & $4(3.4)$ & \\
\hline Divorced & $39(6.6)$ & $9(7.6)$ & \\
\hline Widower & $69(11.7)$ & $17(14.4)$ & \\
\hline
\end{tabular}

A: Above 20 minimum wages (*); $B$ : 10 to 20 minimum wages ( + ); $C: 4$ to 10 minimum wages ( $\neq$ ); $D: 2$ to 4 minimum wages (\$); E: Up to 2 minimum wages (//).

was third in prevalence in the private service $(35.6 \%, \mathrm{p}<0.001)$, while in the public service it was fourth $(33.8 \%, p<0.001)$. Smoking was a factor of great disparity between the two care networks (34\% vs $9.3 \%$; $p<0.001$ ). Most patients presented the association of 2 risk factors in both services (35.1\% vs $40.7 \%$, $\mathrm{p}=0.534$ ) (Table 2).

When the characteristics related to the pathological history of both groups were evaluated, a prevalence of factors related to the patients attended by the private service was observed, with them being a previous history of AMI (7.1\% vs $16.1 \%$, $\mathrm{p}=0.002)$, and previous angioplasty $(4.9 \%$ vs $10.2 \%$; $\mathrm{p}=0.026)$, and prior coronary artery bypass grafting $(0.8 \%$ vs $5.1 \%, p<0.001)$. The prevalence of family history of previous coronary artery disease $(29.4 \%$ vs $44.1 \%, p=0.002)$ and peripheral vascular disease (5.3\% vs $15.3 \%$; $p<0.001$ ) (Table 2 ) are also observed for the patients of the private service.

\section{Coronary reperfusion}

During STEMI, there was a significant disparity between the results obtained by all patients attended at SUS and all those who sought private care regarding the use of PA. For the former, the reperfusion rate was $45.3 \%$ while for the latter it was $79.7 \%(p<0.001)$. In both services, the use of conventional and pharmacological stents was analyzed, and in this aspect an important discrepancy was also observed, since there was a predominance of the use of bare metal stents in SUS (89.5\%, p < 0.001), and DES in the private network (82.4\%, p < 0.001) (Table 3).

\section{Coronary reperfusion in diabetic patients}

In view of the recommendation of guidelines ${ }^{1,3}$ for the use of DES in diabetics, with level of evidence $A$ and indication class II, these patients were grouped in a special subgroup to assess if the recommendations for stent placement are being followed during coronary angioplasty. A total of 199 diabetic patients were seen in the public service; of these, $47.7 \%$ had access to PA and, in most interventions $(91.3 \%)$, bare metal stents were used, while only $8.7 \%$ used DES ( $p<0.001)$. In the private service, 42 diabetics were attended; of these, $78.6 \%$ had access to primary $\mathrm{PCl}$, with placement of drug-eluting 


\section{Original Article}

Table 2 - Pathological background of STEMI patients attended at Sergipe State Hospitals with capacity to undergo primary angioplasty (SUS x Private care)

\begin{tabular}{|c|c|c|c|}
\hline Pathological background & SUS $(n=589)$ & Private network $(n=118)$ & $p$ value \\
\hline \multicolumn{4}{|l|}{ Cardiovascular risk factors, $\mathrm{n}(\%)$} \\
\hline Hypertension & $358(39.2)$ & $84(71.2)$ & 0.033 \\
\hline Diabetes & $199(33.8)$ & $42(35.6)$ & 0.705 \\
\hline Dyslipidemia & $214(36.3)$ & $66(55.9)$ & $<0.001$ \\
\hline Smoking & $200(34.0)$ & $11(9.3)$ & $<0.001$ \\
\hline \multicolumn{4}{|l|}{ Number of risk factors, $\mathrm{n}(\%)$} \\
\hline 0 & $75(12.7)$ & $14(11.9)$ & 0.534 \\
\hline 1 & $191(32.5)$ & $31(26.2)$ & \\
\hline 2 & $207(35.1)$ & $48(40.7)$ & \\
\hline$\geq 3$ & $116(19.7)$ & $25(21.2)$ & \\
\hline \multicolumn{4}{|l|}{ Previous coronary disease, $\mathrm{n}(\%)$} \\
\hline AMI & $42(7.1)$ & $19(16.1)$ & 0.002 \\
\hline Angina pectoris & $94(84.0)$ & $22(18.6)$ & 0.472 \\
\hline Previous Angioplasty & $29(4.9)$ & $12(10.2)$ & 0.026 \\
\hline \multicolumn{4}{|l|}{ Revascularization } \\
\hline Previous & $5(0.8)$ & $6(5.1)$ & 0.001 \\
\hline Family history of early CAD, $n(\%)$ & $173(29.4)$ & $52(44.1)$ & 0.002 \\
\hline Stroke previous, $\mathrm{n}(\%)$ & $41(7.0)$ & $7(5.9)$ & 0.685 \\
\hline Peripheral vascular disease, $\mathrm{n}(\%)$ & $31(5.3)$ & $18(15.3)$ & $<0.001$ \\
\hline
\end{tabular}

AMI: acute myocardial infarction; $C A D$ : coronary artery disease.

Table 3 - Percutaneous coronary angioplasty and use of stents in STEMI patients attended in tertiary Hospitals in the State of Sergipe (SUS x Private network)

\begin{tabular}{|c|c|c|c|}
\hline Coronary angioplasty & SUS $(n=589)$ & Private network $(n=118)$ & $\mathrm{p}$ value \\
\hline Door-to-balloon time, min & $121.2 \pm 107.1$ & $129.8 \pm 90.2$ & 0.48 \\
\hline Primary Angioplasty, n (\%) & $267(45.3)$ & $94(79.7)$ & $<0.001$ \\
\hline \multicolumn{4}{|l|}{ Type of stent used, $n(\%)$} \\
\hline Bare metal & $229(89.5)$ & $16(17.6)$ & $<0.001$ \\
\hline Drug-eluting & $27(10.5)$ & $75(82.4)$ & \\
\hline Non-Primary Angioplasty, n (\%) & $193(32.8)$ & $21(17.8)$ & 0.001 \\
\hline \multicolumn{4}{|l|}{ Type of stent used, $n(\%)$} \\
\hline Bare metal & $166(90.7)$ & $3(14.3)$ & $<0.001$ \\
\hline Drug-eluting & $17(9.3)$ & $18(85.7)$ & \\
\hline
\end{tabular}

stent in $90.6 \%$ of this subgroup of patients $(p<0.001$ ) (Table 4). The mean and standard deviation of the port-balloon time of diabetics seen at SUS versus the private system were $114( \pm 91)$ and $133( \pm 67)$, respectively $(p=0.26)$.

\section{Discussion}

A disparity between the public and private services regarding the performance of $\mathrm{PA}$ and the use of DES for patients with STEMI, especially for diabetics, is observed. It is also worth noting a remarkable overuse of bare metal stents with higher utility rates for the public service, which is in disagreement with the guidelines recommendations. ${ }^{1,3}$

The value found for performing PA at the Unified Health System (SUS) was below the expected average in relation to procedures performed in the North-Northeast (52.5\%), according to a study by Nicolau et al. in 2012. ${ }^{8}$ Primary PCI with the use of stents is considered the gold standard in the treatment of STEMI, ${ }^{1,2}$ and these findings reflect the underuse of this therapy at SUS, which may directly contribute to these patients' prognosis. 
Table 4 - Percutaneous coronary angioplasty and use of stents in diabetic STEMI patients attended in tertiary Hospitals in the State of Sergipe (SUS x Private network)

\begin{tabular}{|c|c|c|c|}
\hline $\begin{array}{l}\text { Coronary angioplasty } \\
\text { In diabetic patients }\end{array}$ & SUS $(n=199)$ & Private network $(n=42)$ & $\mathrm{p}$ value \\
\hline Primary Angioplasty, $\mathrm{n}(\%)$ & $95(47.7)$ & $33(78.6)$ & $<0.001$ \\
\hline \multicolumn{4}{|l|}{ Type of stent used, $n(\%)$} \\
\hline Bare metal & $84(91.3)$ & $3(9.4)$ & $<0.001$ \\
\hline Drug-eluting & $8(8.7)$ & $29(90.6)$ & \\
\hline Non-Primary Angioplasty, n (\%) & $63(31.7)$ & $10(23.8)$ & 0.314 \\
\hline \multicolumn{4}{|l|}{ Type of stent used, $n(\%)$} \\
\hline Bare metal & $52(88.1)$ & $0(0)$ & $<0.001$ \\
\hline Drug-eluting & $7(11.9)$ & $10(100)$ & \\
\hline
\end{tabular}

Although the proportion of patients undergoing PA is higher in the private network $(79.7 \%, \mathrm{p}<0.001)$, this result may still be suboptimal, since Sergipe is small in size, which should facilitate access to Primary Care. Therefore, there is a need to improve the quality of the service provided, with the training of multiprofessional teams for the rapid and adequate diagnosis of AMI both in the intra- and prehospital settings, so that access to reperfusion therapies for myocardial infarction is optimized.

It is also observed that $82.4 \%$ of the patients seen at the private network received DES in the PA, while in the public network only $10.5 \%(p<0.001)$ received them. This result in Sergipe at SUS is below the rate of use of DES in the public network throughout Brazil (14\%) between the years 2004 and 2005, when these devices were not yet released for use in SUS, according to data of the CENIC Registry. ${ }^{9}$ The indication for use of DES follows specific criteria determined by the $\mathrm{SBHCl}$, such as stenosis in the single remaining vessel, intra-stent restenosis, and diabetics with stenosis that can be treated with PA. ${ }^{3}$ The wide low use of DES in the public network, however, is justified by possible additional expenses inherent to the procedure. These devices have a much higher cost compared to bare metal ones, and require sustained dual antiplatelet therapy, which further increases their effective cost. ${ }^{10}$

On the other hand, the large use of these stents at the private network (in approximately $80 \%$ of the total analyzed) may suggest the lack of an adequate protocol of use instructions, extrapolating the classic and evidence-based indications. The high financial cost that this therapy entails is expressive; thus, the cost-effectiveness of DES is potentially questionable in such situations. ${ }^{11,12}$

An American study conducted in 2007 by Beohar et al. ${ }^{12}$ showed that the use of DES in patients without formal indications that were not tested by clinical trials was related to more severe outcomes when compared to those patients who had a standard indication. Another more recent American study, conducted in 2017, ${ }^{13}$ argues that the superiority of DES should not automatically translate into the end of the use of bare metal stents, since the latter still have a potential advantage in specific situations because of the short-term need for antiplatelet aggregation. Patients who will undergo another surgical procedure, either cardiac or not, or those who have high risk of bleeding strongly benefit from the use of metal prostheses. Therefore, DES should not be indiscriminately and randomly used. ${ }^{13}$

Regarding the use of DES for diabetic patients, the results also revealed a disparity when the public and private networks were compared. During PA, the DES use rate in diabetics was $8.7 \%$ vs. $90.6 \%, p<0.001$. It is worth mentioning that diabetes mellitus is one of the most common clinical conditions with increasing incidence. They represent a special group of patients facing coronary angioplasty, with large international randomized studies demonstrating high rates of late reintervention and restenosis during the use of conventional prostheses. ${ }^{14-16}$ Because in such cases the cost-effectiveness ratio makes the use of the technology economically viable, with less impact on the budget, it is known that DES are allowed for use at SUS in these situations. ${ }^{9}$ However, the data found in the present study also reveal a much lower use of this technology in the public service.

These findings point to the fact that even after the creation of national legislation, recommendations for drug-eluting stent use have not been followed in Sergipe. In this scenario, diabetics receiving bare metal stents would not have the benefit of reducing morbidity and mortality when compared with the use of DES, as demonstrated in international studies, such as DIABETES, SCORPIUS and ISARDESIRE. ${ }^{17-19}$

Thus, failure to follow the current recommendations triggers a warning signal for the need to monitor the adequate implementation of public health policies in Sergipe, as well as recommend the adoption of a system of governance in the use of stents according to criteria adopted by the guidelines in force.

The present study has some limitations. First, it is an observational study, in the form of a record. Therefore, there is a possibility that other aspects, other than those found in the analysis, may have influenced the choice of the stent, including logistic phenomena, such as occasional lack of a given material. Secondly, the low level of education, especially in the SUS group, impaired self-information regarding personal medical history, with a tendency to underestimate risk factors and comorbidities. Third, late follow-up of patients was not performed. As a consequence, it was not possible to evaluate whether the disparity in the indication resulted in a significant impact on the restenosis rate. 


\section{Conclusion}

The study reveals a disparity in the use of DES during coronary angioplasty among patients attended at SUS and at the private network, either in the total sample or in the subgroup of diabetic patients, since lower rates of DES use were observed at SUS in both populations. This fact shows failure to follow an adequate protocol in the use of DES and their classic indications, which increases treatment cost-effectiveness. In addition, the diabetics in the public network have been mostly receiving bare metal stents, even after legislation has been in place to regulate the use of DES in this special subgroup of patients. Therefore, it is necessary to monitor the proper implementation of health policies, and to reassess therapeutic strategies and their real cost-effectiveness.

\section{Author contributions}

Conception and design of the research: Oliveira JC, Oliveira JC, Barreto-Filho JAS; Acquisition of data: Oliveira JC, Oliveira LCS, Oliveira JC, Lima TCRM, Arcelino LAM, Silva ISBS, Barreto-Filho JAS; Analysis and interpretation of the data: Oliveira JC, Oliveira LCS, Barreto IDC, Almeida-Santos MA, Sousa ACS, Barreto-Filho JAS; Statistical analysis: Oliveira JC, Barreto IDC, Barreto-Filho JAS; Obtaining financing: Oliveira JC, Barreto-Filho JAS; Writing of the manuscript:

\section{References}

1. Piegas LS, Timerman A, Feitosa GS, Nicolau JC, Mattos LAP, Andrade MD, et al. V Diretriz da Sociedade Brasileira de Cardiologia sobre Tratamento do Infarto Agudo do Miocárdio com Supradesnível do Segmento ST. Arq Bras Cardiol. 2015;105(2):1-105.

2. Steg PG, James SK, Atar D, Badano LP, Blömstrom-Lundqvist C, Borger MA, et al. Task Force on the management of ST-segment elevation acute myocardial infarction of the European Society of Cardiology (ESC). ESC Guidelines for the management of acute myocardial infarction in patients presenting with ST-segment elevation. Eur Heart J. 2012;33(20):2569-619.

3. Lima VC, Mattos LA, Caramori PR, Perin MA, Mangione JA, Machado $\mathrm{BM}$, et al. Consenso de especialistas ( $\mathrm{SBC} / \mathrm{SBHCl}$ ) sobre o uso de stents farmacológicos: recomendações da sociedade brasileira de cardiologia/ sociedade brasileira de hemodinâmica e cardiologia intervencionista ao sistema único de saúde. Arq Bras Cardiol. 2006;87(4):e162-7.

4. Yang TH, Park SW, Hong MK, Park DW, Park KM, Kim YH, et al. Impact of diabetes mellitus on angiographic and clinical outcomes in the drug-eluting stents era. Am J Cardiol. 2005;96(10):1389-92.

5. Moreira AC, Sousa AG, Costa JJ, Costa AR, Maldonado GA, Cano MN, et al. Evolução tardia após intervenção coronária percutânea com stents farmacológicos em pacientes diabéticos do Registro DESIRE (Drug-Eluting Stents In the REal world). Revista Brasileira de Cardiologia Invasiva. 2008;16(2):185-92.

6. Rassi Jr A. Análise econômica dos Stents coronarianos farmacológicos no Brasil: para todos ou para poucos pacientes?. Arq Bras Cardiol. 2007;88(4):376-7.
Oliveira JC, Lima TCRM, Arcelino LAM, Silva ISBS, Sousa ACS, Barreto-Filho JAS; Critical revision of the manuscript for intellectual content: Oliveira JC, Oliveira LCS, Oliveira JC, Almeida-Santos MA, Lima TCRM, Barreto-Filho JAS.

\section{Potential Conflict of Interest}

No potential conflict of interest relevant to this article was reported.

\section{Sources of Funding}

This study was funded by CNPq.

\section{Study Association}

This article is part of the thesis of Doctoral submitted by Jussiely Cunha Oliveira, from Universidade Federal de Sergipe.

\section{Ethics approval and consent to participate}

This study was approved by the Ethics Committee of the Universidade Federal de Sergipe under the protocol number 483.749. All the procedures in this study were in accordance with the 1975 Helsinki Declaration, updated in 2013. Informed consent was obtained from all participants included in the study.
7. Brasil. Ministério da Saúde. Tecnologia e Insumos Estratégicos. Portaria no 29 de 27 de agosto de 2014. Disponível em: <http://www.saude.gov.br/ conitec > Acesso em: junho de 2017.

8. Nicolau JC,Franken M, Lotufo PA, Carvalho CA, Marin Neto JA, Lima FG, et al. Utilização de terapêuticas comprovadamente úteis no tratamento da coronariopatia aguda: comparação entre diferentes regiões brasileiras. análise do registro brasileiro de síndromes coronarianas agudas (BRACE - Brazilian Registry on Acute Coronary Syndromes). Arq Bras Cardiol. 2012;98(4):282-9.

9. Cardoso CO, Quadros AS, Mattos LA, Gottschall CA, Sarmento-Leite RE, Marin-Neto JA. Perfil de uso dos stents farmacológicos no Brasil: dados da Central Nacional de Intervenções Cardiovasculares (CENIC). Arq Bras Cardiol. São Paulo. 2007;89(6): 356-61.

10. Amin AP, Spertus JA, Cohen DJ, Chhatriwalla A, Kennedy KF, Vilain K, et al. Use of drug-eluting stents as a function of predicted benefit: clinical and economic implications of current practice. Arch Intern Med. 2012;172(4):1145-52.

11. Steinberg DH, Mishra S, Javaid A, Slottow TL, Buch AN, Roy P, et al. Comparison of effectiveness of bare metal stents versus drug-eluting stents in large (> or =3.5 mm) coronary arteries. Am J Cardiol. 2007;99(5):599-602.

12. Beohar N, Davidson CJ, Kip KE, Goodreau L, Vlachos HA, Meyers SN, et al. Outcomes and complications associated with off-label and untested use of drug-eluting stents. JAMA. 2007; 297(18):1992-2000.

13. Colombo A, Giannini F, Briguori C. Should westill have bare-metal stents available in our catheterization laboratory? J Am Coll Cardiol. 2017; 70(5): 607-19. 
14. de Waha A, Dibra A, Byrne RA, Ndrepepa G, Mehilli J, Fusaro M, et al. Everolimus-eluting versus sirolimus-eluting stents: a meta-analysis of randomized trials. Circ Cardiovasc Interv. 2011;4(4):371-7.

15. Kastrati A, Mehilli J, Pache J, Kaiser C, Valgimigli M, Kelbaek H, et al. Analysis of 14 trials comparing sirolimus-eluting stents with baremetal stents. N Engl J Med. 2007;356(3):1030-9.

16. Greenhalgh J, Hockenhull J, Rao N, Dundar Y, Dickson RC, Bagust A. Drug-eluting stents versus bare metal stents for angina or acute coronary syndromes. Cochrane Database of Syst Rev. 2010;(5):CD004587

17. Jimenez-Quevedo P, Sabate M, Angiolillo DJ, Alfonso F, Hernández-Antolín $R$, SanMartín M, et al. Long-term clinical benefits of sirolimus-eluting stent implantation in diabetic patients with de novo coronary stenoses: longterm results of the DIABETES trial. Eur Heart J. 2007; 28(16):1946-52.

18. Baumgart D, Klauss V, Baer F, Hartmann F, Drexler H, Motz W. One-year results of the SCORPIUS study: a German multicenter investigation on the effectiveness of sirolimus-eluting stents in diabetic patients. J Am Coll Cardiol. 2007;50(17):1627-34.

19. Kastrati A, Mehilli J, von Beckerath N, Dibra A, Hausleiter J, Pache J,et al. Sirolimu-seluting stent or paclitaxel-eluting stent versus balloon angioplasty for prevention of recurrences in patients with coronary instent restenosis: a randomized controlled trial. JAMA. $2005 ; 293(2): 165-71$. 